\title{
CHEMICAL PROPERTIES OF THE SEA WATER IN THE NEIGHBOURHOOD OF THE LABADIE BANK
}

\author{
By L. H. N. Cooper, D.Sc., F.R.I.C.
}

Chemist at the Plymouth Laboratory

(Text-figs. I-3)

A number of excursions to the Celtic Sea have been made, first, to obtain for Dr D. P. Wilson water as contrasted as possible with that in the English Channel near Plymouth, and secondly to obtain answers to hydrographical queries. This paper presents some of the chemical findings which may prove to be relevant to Wilson's investigations on the development of the young planktonic stages of invertebrates. Since not all sea water in the Celtic Sea was likely to be equally suitable for his work, some means was needed for quickly assessing waters on the spot. There are a number of objections to the use of phosphate or other chemical analyses on board so that examination of plankton hauls was chosen. Suitable water was selected on the basis of the bulk and variety of zooplankton and the presence of species known to indicate 'elegans' water. The $2 \mathrm{~m}$. stramin ring-trawl, fished for the standard half-hour oblique haul, was used.

On the earlier cruises the water was sampled at the surface with a wooden bucket and filled into carboys through a wooden funnel fitted with a 200-meshesto-the-inch silk strainer. The occasional high values for phosphorus compounds and iron found in surface water suggest that various kinds of dross may accumulate there so that, in the later work, collection was made from $20-30 \mathrm{~m}$. depth through a rubber hose. This water did not pass through the pump used.

All carboys were very well cleaned by Mr F. A. J. Armstrong personally, using water-white technical grade sulphuric acid, followed by Plymouth tap water and plenty of distilled water. Chromic cleaning mixture was never used. The bark bung was covered with a clean piece of waterproof paper. The wooden bucket and funnel are well cared for and were vigorously swilled with sea water on the spot. Soap was never used. The rubber hose was washed out by running water through it to waste for several minutes.

'Celtic' water, shown by Wilson's experiments to promote more healthy growth and development than 'Outside' or 'Channel' water, was drawn from the following positions which are shown by circles in Fig. I.

\begin{tabular}{|c|c|c|c|}
\hline Date & Lat. & Long. & General position \\
\hline 30. vi. 48 & $50^{\circ} 00^{\prime} \mathrm{N}$. & $7^{\circ} \mathrm{IO}^{\prime} \mathrm{W}$ & 35 miles west of Scilly Isles \\
\hline 10. iii. 49 & $50^{\circ} 36^{\prime} \mathrm{N}$. & $8^{\circ} 04^{\prime} \mathrm{W}$. & Over Labadie Bank \\
\hline 29. iv. 50 & $50^{\circ} 33^{\prime} \mathrm{N}$. & $8^{\circ} 5 \mathrm{I}^{\prime} \mathrm{W}$. & 20 miles west of Labadie Bank (Station 64 ) \\
\hline
\end{tabular}




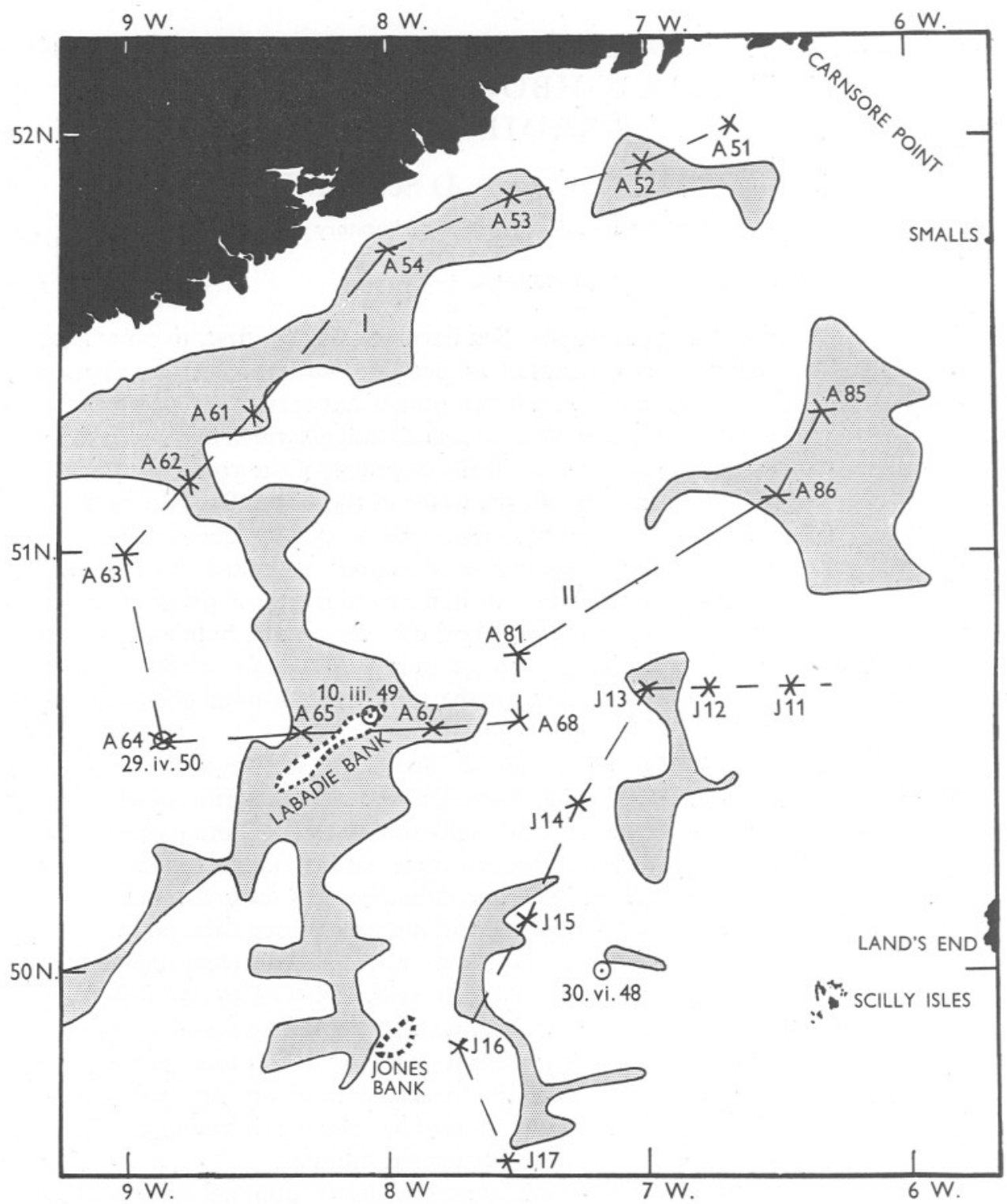

Fig. I. Areas of mud and ooze (stippled) in the Celtic Sea (after Laurie Norie and Wilson's chart (I9I9) of the Outer Grounds of the English Channel). Stations, marked by crosses, worked in April I950 (prefixed by letter A) and in June I950 (prefixed by letter J). Stations, marked by circles and dated, where waters for Dr Wilson's experiments (I95I) were collected. 
For each of these waters a description of the chemical properties has already been given in Wilson (I95I, pp. 3, 5, I0).

No attempt has been made to contrast one Celtic Sea water with another. We cannot say whether waters which yielded sparse catches with the ring trawl would have caused poor development of Echinus and other invertebrates. The positive conclusions were: (a) water collected in spring over or a few miles to the west of the Labadie Bank was favourable for the development of young Echinus esculentus, a sea-urchin, and Sabellaria alveolata, a polychaete worm; $(b)$ water collected at midsummer 35 miles west of Scilly was favourable for development of the polychaete Ophelia bicornis.

It is not yet possible to say how far these conclusions may be generalized for other seasons and other areas in the Celtic Sea. None the less, the March I949 search for a suitable water was conducted much at random and several poor plankton catches were taken before the rich one over the Labadie Bank. In April I950, also, suitable water was found not far away. Since other lines of evidence are pointing to the Labadie area as important in the economy of the Celtic Sea, it is proposed to report them here.

Around the Labadie Bank weak tides should facilitate the accumulation of detritus in the deeper water and the deposition of fine sediment. Much mud and ooze on the sea-bed surrounding the bank is shown on the chart of the outer grounds of the English Channel, published in I9I9 by Laurie Norie and Wilson and based on Admiralty soundings with the primed lead (Fig. I). The areas of mud and ooze are stippled. Richness of this mud in organic matter still needs to be demonstrated.

In April 1950 hydrographical stations were worked on a course laid over the bank. Due to overcast weather there is a possible error of 5 miles or so in the dead reckoning of some of the positions so that stations 68 and $8 \mathrm{I}$ shown as lying outside of the muddy area may actually have lain within it. It was anticipated that regeneration and breakdown of suspended detritus and of mud would be revealed by a notably higher content of total and phosphate phosphorus in the bottom water. The results confirmed the hypothesis although they did not prove it (Fig. 2).

At stations 62, 6I, 53 and 52 on Section I (Fig. 2) and at station 67 on Section II (Fig. 3) which all overlay mud or ooze, the content of phosphatephosphorus in the bottom water was relatively high. Total phosphorus was high by the same amount, providing strong confirmation of this enrichment of the bottom water. At station 8I a single analysis on the bottom water gave a high content of total phosphorus but no parallel analysis of phosphatephosphorus was made.

At station 85 over another area of mud in the 'submerged estuary' of the 'Irish Channel River', high content of total- and phosphate-phosphorus was also observed in the deeper water. The neighbouring station 86 over mud did 
not show the phenomenon, whilst station 65 over mud to the west of Labadie Bank showed it only weakly.

There was no evidence of bottom regeneration of any form of phosphorus at the remaining forty-three stations worked in April I950 over non-muddy

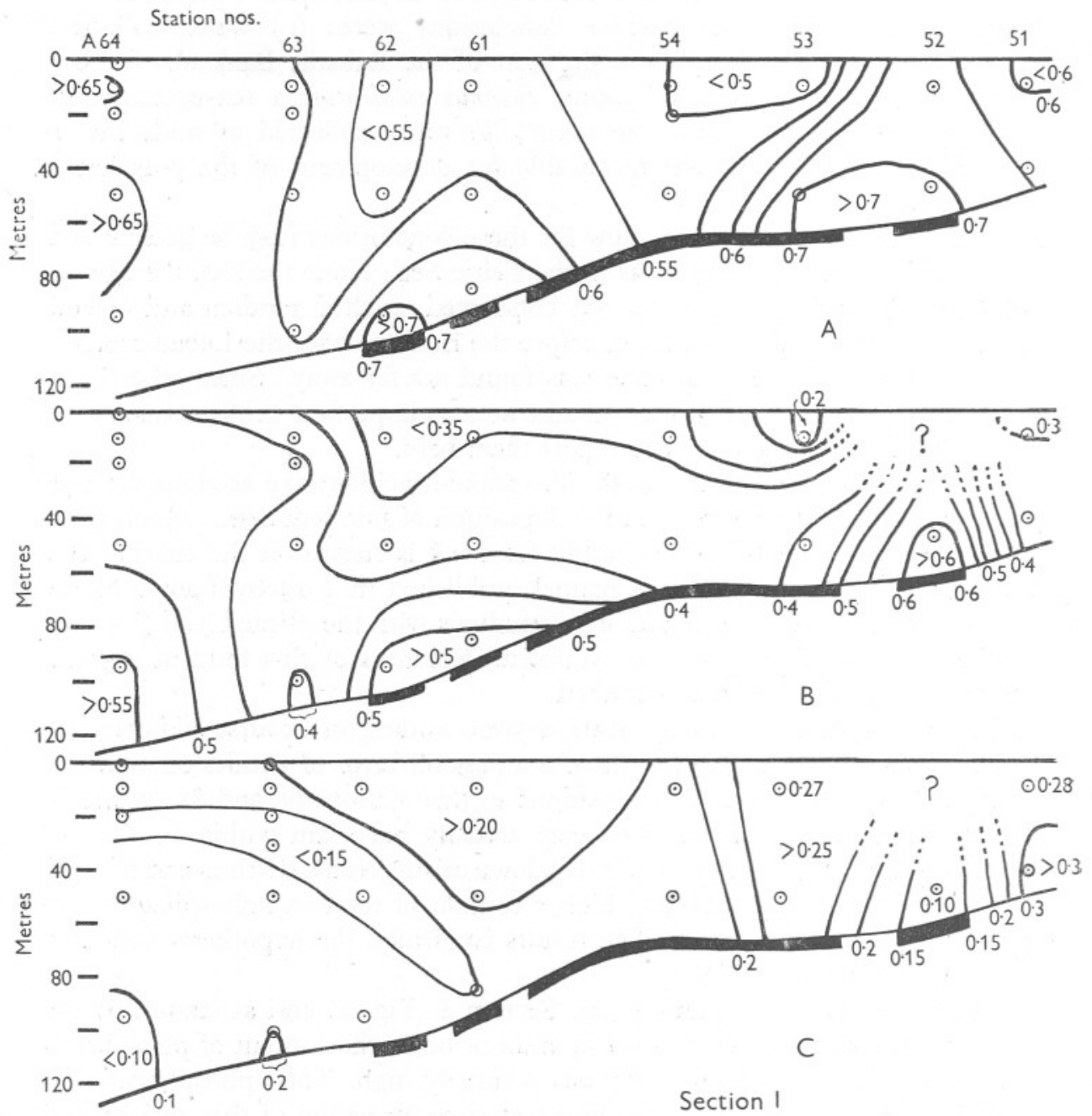

Fig. 2. Vertical Section I of stations worked over mud or ooze for (A) total phosphorus, (B) phosphate-phosphorus and (C) organic phosphorus in the Celtic Sea, 25-29 April 1950. Areas of mud and ooze are shown by thickening of the bottom lines of the sections.

bottoms. On the June cruise also there was no evidence of bottom regeneration from the non-muddy areas; the course from stations I2 to I7 (Fig. I) lay over small muddy patches, although only one actual station was so placed. Inter- 
pretation of the small differences observed, complicated by thermal stratification, is difficult.

Enrichment of the bottom water by breakdown of suspended detritus or of ooze and mud is unlikely to be confined to phosphate. Other nutrients and

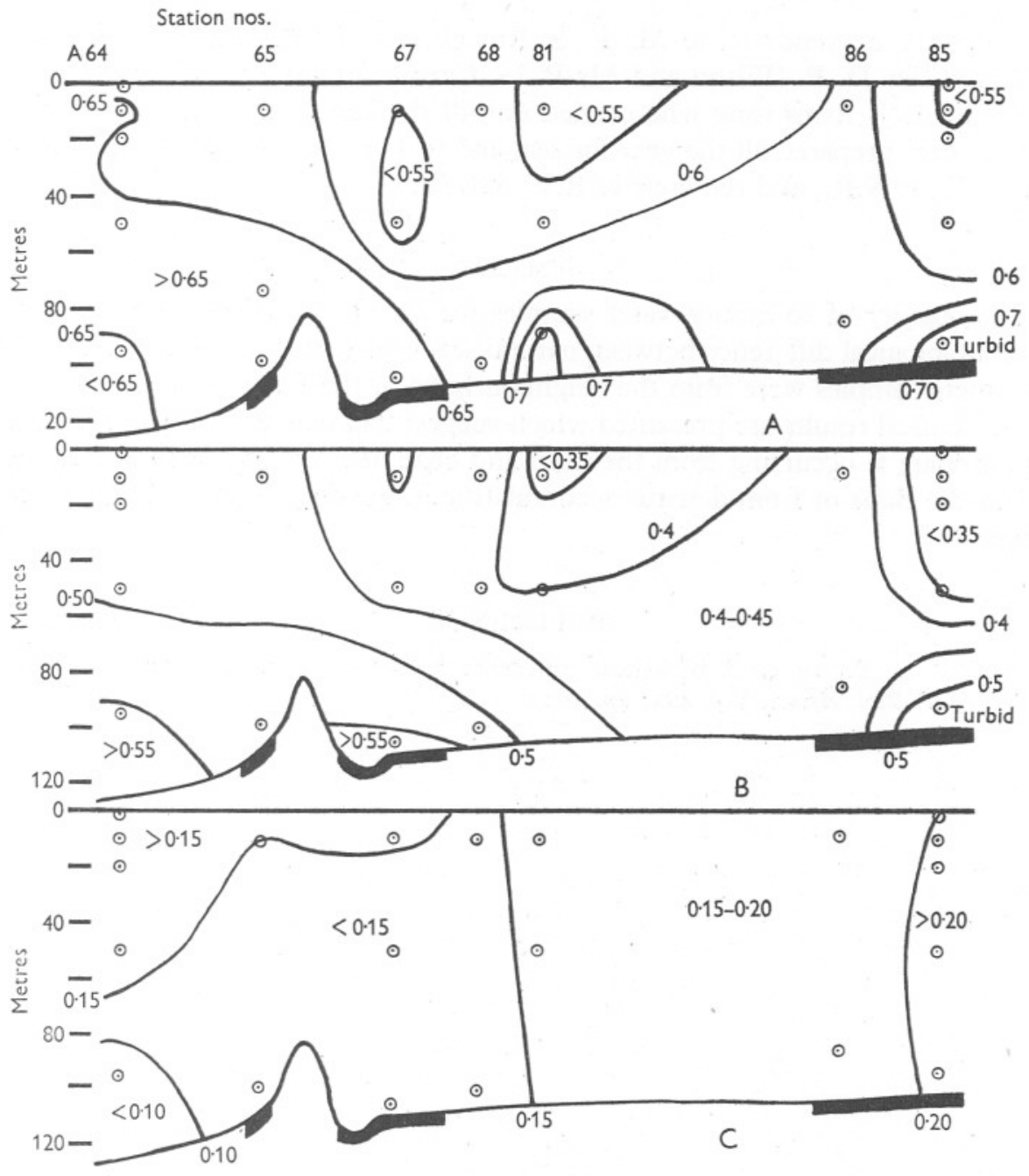

Section II

Fig. 3. Vertical Section II of stations worked over mud or ooze, as in Fig. 2.

growth-affecting substances are likely to accompany it. Rich catches of the larger zooplankton may be had from many parts of the Celtic Sea where a number of very different methods of enrichment are possible. None the less, it is a suggestive coincidence that two of the water samples which proved 
successful in Wilson's experiments were taken in the Labadie area, where regeneration of phosphate and presumably other growth-promoting substances was occurring in the deeper water. The neighbourhood of the Labadie Bank should repay intensive study.

Thanks are tendered to Mr F. S. Russell, Dr H. W. Harvey, Mr G. A. Steven, Dr D. P. Wilson and Mr P. G. Corbin for valuable discussions, to Mr F. A. J. Armstrong who carried out all the chemical analyses and with great care prepared all the gear for sea, and to Lieut.-Cmdr. C. A. Hoodless, D.S.C., R.N.R., and the crew of R.V. Sabella.

\section{SUMMARY}

The manner of collecting water samples for Dr D. P. Wilson's experiments on a biological difference between natural sea waters has been described. Two of these samples were from the neighbourhood of the Labadie Bank.

Chemical results are presented which suggest that extensive regeneration of phosphate is occurring from the mud and ooze deposits which surround the Labadie Bank or from detritus accumulating in the deeper water due to weak tides.

\section{REFERENCE}

Wilson, D. P., I95I. A biological difference between natural sea waters. fourn. Mar. Biol. Assoc., Vol. xxx, pp. I-20. 